C2006 IEEE. Personal use of this material is permitted. However, permission to reprint/republish this material for advertising or promotional purposes or for creating new collective works for resale or redistribution to servers or lists, or to reuse any copyrighted component of this work in other works must be obtained from the IEEE. 


\title{
Predicting the Dynamic Nature of Risk
}

\author{
Omar Khadeer Hussain ${ }^{1}$, Elizabeth Chang ${ }^{1}$, Farookh Khadeer Hussain ${ }^{1}$, Tharam S. Dillon ${ }^{2}$ \\ and Ben Soh ${ }^{3}$ \\ ${ }^{1}$ School of Information Systems, Curtin University of Technology, WA, Australia \\ Email :\{ Omar.Hussain, Elizabeth.Chang, Farookh.Hussain\}@cbs.curtin.edu.au \\ ${ }^{2}$ Faculty of Information Technology, University of Technology, Sydney, NSW, Australia \\ Email: tharam@it.uts.edu.au \\ ${ }^{3}$ Dept. of Computer Science and Computer Engineering, La Trobe University, VIC, Australia \\ Email:ben@cs.latrobe.edu.au
}

\begin{abstract}
The trusting peer in order to determine the likelihood of the loss in its resources might analyze the Risk before engaging in an interaction with any trusted peer. This likelihood of the loss in the resources is termed as Risk in the interaction. Risk analysis is important in e-commerce transactions because of the vast literature that argues that the decision to buy is based on the Risk-adjusted cost-benefit analysis. If the trusting peer can determine the future Riskiness value or reputation of a trusted peer for the time period of its interaction, before engaging in an activity with it, then it can ease its decision making process of whether to interact with the trusted peer or not. In this paper we present such a novel method which predicts the dynamic nature of Risk and determines the future Riskiness value of the trusted peer, before the interaction starts, thus helping the trusting peer considerably in making its decision.
\end{abstract}

\section{Introduction}

The users of the internet are being benefited with the numerous facilities that have evolved with its development. These facilities have simplified the way business interactions are carried out over the internet [1]. This process of carrying business interactions over the internet came to be known as e-commerce transactions. There are two types of architectures through which ecommerce transactions can be conducted. They are:

a) Client-Server Business Architecture, and

b) Peer-to-Peer Business Architecture.

Some of the characteristics of Peer-to-Peer transactions are:

1. Absence of a server between the peers.

2. Nature of interaction between the Peers, i.e. the peers interact with each other directly, rather than through a server as compared to a centralized transaction

3. Peers can forge or create multiple identities in a decentralized transaction, and there is no way of checking the identity claimed by the Peer to be genuine or not. On the other hand, in a centralized transaction it can be checked, as the information about the Peers is stored in the server. The above properties clearly show that a decentralized transaction carries more Risks and hence merits more detailed investigations. Risk is important in the study of behavior in ecommerce, because there is a whole body of literature based in rational economics that argues that the decision to buy is based on the Riskadjusted cost-benefit analysis [2]. Thus it commands a central role in any discussion of e-commerce that is related to a transaction.

In this paper we present a novel approach by which the trusting peer analyzes the Risk in dealing with a trusted peer, by predicting its future Riskiness value beforehand for the duration of their interaction. Based on the Riskiness value achieved it can then decide whether or not to interact with the trusted peer. This paper is organized into 7 sections. In section 2 we discuss about our related work which forms the base for predicting the future Riskiness value of the trusted peer. In section 3 and section 4 we propose our model of Riskiness value prediction and explain the model with an example in section 5. In section 6 we prove the accuracy of the Riskiness value predicted and finally in section 7 we conclude the paper.

\section{Related Work}

In order to analyze and measure the Risk that could be involved in dealing with a particular trusted peer we defined the term Riskiness. As discussed in Hussain et al [3] Riskiness is defined as the numerical value that is assigned to the trusted peer by the trusting peer after its interaction with it. The Riskiness value shows the level of Risk of the trusted peer on the Riskiness scale. The Riskiness scale represents different levels of Risk that could be present in the interaction. The domain of the Riskiness scale ranges from $(-1,5)$ as shown in 


\begin{tabular}{|c|c|c|c|}
\hline $\begin{array}{l}\text { Riskiness } \\
\text { Levels }\end{array}$ & $\begin{array}{l}\text { Magnitude of } \\
\text { Risk }\end{array}$ & $\begin{array}{l}\text { Riskiness } \\
\text { Value }\end{array}$ & Star Rating \\
\hline Unknown & . & .1 & Not Displayed \\
\hline Totally Risky & $\begin{array}{l}90 \cdot 100 \% \text { of } \\
\text { Risk }\end{array}$ & 0 & Not Displayed \\
\hline $\begin{array}{l}\text { Extremely } \\
\text { Risky }\end{array}$ & $\begin{array}{l}71-90 \% \text { of } \\
\text { Risk }\end{array}$ & 1 & From 20 tow \\
\hline Largely Risky & $\begin{array}{l}51-70 \% \text { of } \\
\text { Risk }\end{array}$ & 2 & 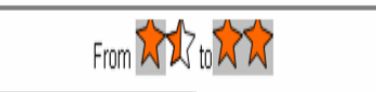 \\
\hline Risky & $\begin{array}{l}26-50 \% \text { of } \\
\text { Risk }\end{array}$ & 3 & From Whith to \\
\hline $\begin{array}{l}\text { Largely } \\
\text { UnRisky }\end{array}$ & $\begin{array}{l}11-25 \% \text { of } \\
\text { Risk }\end{array}$ & 4 & From WWAW tow \\
\hline UnRisky & $\begin{array}{l}0-10 \% \text { of } \\
\text { Risk }\end{array}$ & 5 & From WW \\
\hline
\end{tabular}

Figure 1 Showing the Riskiness scale and its associated levels

figure 1. The Riskiness value is assigned to the trusted peer by the trusting peer after assessing the level of its uncommitted behavior in the interaction with respect to the promised commitment. We have defined a methodology by which the trusting peer assess the behavior of the trusted peer in order to determine the un-committed behavior in the interaction and subsequently its Riskiness value in Hussain et al [3].

But the Riskiness value is assigned to the trusted peer by the trusting peer after its interaction with it. As mentioned in the previous section the decision to proceed in the transaction is based on the Risk adjusted cost benefit analysis. Hence it would be much easier for a trusting peer to decide whether to proceed in an interaction or not with a particular trusted peer if it knows an indication of Risk that could be present in their interaction, before starting it.

Before starting an interaction the trusting peer can analyze the Risk that could be present in its interaction with the trusted peer by asking about its reputation from other peers, if it has no previous interaction history with it. Carter and Ghorbani [4] believe that in the event of total ignorance, assessment from other peer should be relied upon. So if the trusting peer hasn't previously interacted with the trusted peer, then it use its reputation as an alternative in analyzing the Risk and hence in decision making. The trusting peer queries for recommendations from other peers specifying the context of its interaction to determine the reputation of the trusted peer on the Riskiness scale in that particular context. The peers, who had interacted with the trusted peer previously in the context of the trusting peer's query, reply back with their recommended Riskiness value. The recommending peers reply back in the form of Risk set as their recommendation. The Risk set contains the recommended Riskiness value for the trusted peer. As mentioned in Hussain et al [5], the Risk set is an ordered way of giving recommendations so that it is easier for the trusting peer to understand and assimilate them.

The format of the Risk set is:

\{TP1, TP2, Context, CR, R', (Assessment Criteria, Commitment level), R, Cost, Start time, End time, RRP\}

Where TP1 is the Trusting peer in the interaction,

TP2 is the Trusted peer in the interaction,

Context represents the context of the interaction,

CR represents the Current Riskiness value of the trusted peer before the transaction,

R' shows the predicted Riskiness value of the trusted peer depending on its past values,

(Assessment Criteria, Commitment level) shows the factors or bases which the recommending peer used in its interaction with the trusted peer to assign it a Riskiness value. Commitment level specifies whether the particular criterion was fulfilled by the trusted peer or not according to the expected behavior,

$\mathrm{R}$ is the Riskiness value assigned by the recommending peer to the trusted peer after the interaction, which is also the recommended Riskiness value,

Cost represents the cost of the interaction,

Start Time is the time at which the interaction started,

End time is the time at which the interaction ended,

RRP is the Riskiness value of the recommending peer while giving recommendations. This determines whether the recommending peer is trustworthy or not.

As mentioned before the Riskiness value is assigned to the trusted peer after assessing the level of uncommitment in its actual commitment with respect to the promised commitment. When the trusting peer solicits for recommendation about a trusted peer in a particular context, then it should consider replies from peers who had interacted with the trusted peer previously in the same context. But it is highly possible that the criteria of the recommending peers which they used to determine the Riskiness value of the trusted peer and the criteria of the trusting peer asking for recommendations might not be the same. The Riskiness value that the recommending peers recommend is according to the criteria of their interaction. Further the recommending peer giving recommendations might be giving un-trustworthy recommendation too. The trusting peer has to consider all these scenarios before if it assimilates the recommendations to determine the Riskiness value or the reputation of the trusted peer.

We have developed a methodology by which the trusting peer determines the Riskiness value of the trusted peer by assimilating the recommendations according to the criteria or its interaction in Hussain et al [6]. To determine the trustworthiness of the recommendations, each recommending peer is assigned with a Riskiness value called as the Riskiness value of the Recommending peer. We propose that if the Riskiness value of the 
Recommending peer is with in the range of $(-1,1)$ then it can be concluded that it is giving trustworthy recommendation. The trusting peer takes only the trustworthy and unknown recommendations into consideration and leaves out the un-trustworthy recommendations while assimilating them according to its criteria. The process of determining the Riskiness value of the recommending peer is explained in Hussain et al [7]. Further while assimilating the recommendations, the trusting peer should evaluate the Riskiness value of the trusted peer according to the time of the recommendations. As mentioned in Hussain et al [8] Risk varies according to the time. It is not possible for a particular peer to have the same impression of a trusted peer throughout its interaction. Hence we proposed that the trusting peer while assimilating the recommendations should give more importance to the recommendations which are in the recent time slot of its interaction as compared to the far recent ones. The trusting peer considers all these scenarios when it assimilates the recommendations and determines the Riskiness value of the trusted peer according to its criteria. It is possible that before starting an interaction, the trusting peer might have to choose from a set of possible trusted peers with whom to interact with in a given context. By using the methodology of Hussain et al [7] it can ease its process of decision making by soliciting and assimilating the recommendations to determine the Riskiness value of each trusted peer according to its criteria.

As mentioned earlier, Risk varies according to time. It is not possible for a trusting peer to have the same impression of the trusted peer that it had at a particular time throughout its interaction. Hence after determining the Riskiness value of the trusted peers by assimilating the recommendations according to the criteria of its interaction, the trusting peer can decide better with which peer to interact with, or whether to interact or not with a trusted peer, if it analyzes the future Riskiness values of the trusted peer for the duration of its interaction with it. The future Riskiness value for the trusted peer is predicted based on the recommendations achieved by the recommending peers and the criteria of the trusting peer's interaction. The process of determining the future Riskiness value of a trusted peer by considering its past Riskiness value is proposed in the next section.

\section{Classification of Time Periods}

Risk in peer-to-peer and decentralized transactions is defined as the likelihood that the trusted peer will not act as expected by the trusting peer resulting in the loss of resources involved in the transaction [9]. This 'likelihood' varies throughout the transaction depending on the behavior of the trusted peer and hence it is dynamic. Some of the possible scenarios for the variance in the likelihood are:

1. The trusting peer's expectations are not being met by the behavior of the trusted peer.

2. The recommendations that the trusting peer gets from the recommending peers might either strengthen or lessen its belief in the trusted peer's capability to complete the interaction, varying the likelihood of loss too accordingly.

We term the reputation of a peer at a given context and at a given time ' $t$ ' which can be either at the current, past or future time as its Riskiness value.

The process of determining the future Riskiness value of a peer given its current or past Riskiness value is called as Riskiness value prediction.

With the proposed method the trusting peer can find the possible future reputation or Riskiness value of a trusted peer at a given future point of time ' $t+1$ '. Hence the total boundary of time which the trusting peer takes into consideration to analyze and predict the Riskiness value of the trusted peer is defined as the time space.

The trusting peer in order to predict the reputation or the Riskiness value of a trusted peer at time ' $t+1$ ' to analyze its behavior, should know its reputation or Riskiness value from its time space till time ' $t$ '. The total time of interaction between the trusting peer and trusted peer depends on the context. The trusting peer can analyze the Risk in the interaction better and decide whether to interact or not with the trusted peer, if it predicts the Riskiness value of the trusted peer over the time period of its interaction with it. But as mentioned earlier Risk is dynamic and keeps on changing from time to time. If the time space is huge then it is not possible for the trusting peer to have the same impression for the trusted peer throughout that it had at a particular time. Hence the total time space is divided into different nonoverlapping parts and the Riskiness value of the trusted peer is analyzed and predicted in each of those parts. These different non-overlapping parts are called as time slots.

The time at which the trusting peer or any other peer giving recommendation dealt with the trusted peer in the time slot is called as time spot.

For explanation sake let us suppose that the trusting peer wants to predict the behavior of the trusted peer for over a period of 28 days, and wants to analyze the behavior on a weekly basis. Hence the total time space is 28 days and the time slot is of 7 days. The number of time slots in this time space will be 4 .

\section{Riskiness Value Prediction}

As mentioned earlier the trusting peer in order to predict the reputation or the future Riskiness value of the 
trusted peer at time ' $t+1$ ' should know its Riskiness value from its time space till time ' $t$ '. If the trusting peer hasn't previously interacted with the trusted peer in the context of its present interaction, then it can determine its previous reputation or Riskiness values till time ' $\mathrm{t}$ ' by soliciting recommendations from other peers. But even in the same context, each recommending peer might have different criteria in its interaction and the Riskiness value which it recommends to the trusting peer is according to the criteria of its interaction. It is possible that the trusting peer asking for recommendations might have different criteria in its interaction as compared with those of the recommendations from the recommending peers. Hence the trusting peer should take only those recommendations into consideration to predict the future Riskiness value of the trusted peer whose criterions are similar to those in its interaction.

In Hussain et al [7] we have defined the process by which the trusting peer assimilates the recommendations according to the criteria of its interaction and determines the Riskiness value of the trusted peer in the time slot ' $t$ ' of its interaction with it. We propose that the trusting peer in order to predict the future Riskiness value of the trusted peer at time ' $t+1$ ' should consider all the recommendations which it utilized in determining the Riskiness value of the trusted peer at time ' $t$ '.

In order to predict the future Riskiness value of the trusted peer, the trusting peer has to first decide about the total time space over which it is going to analyze the behavior and the Riskiness values of the trusted peer. Within the time space, the trusting peer should determine the duration of each time slot in which it will analyze the behavior of the trusted peer. Once it knows the duration of each slot it can determine the number of time slots in the given time space and analyze its reputation or Riskiness value in each time slot.

Our method of Riskiness value prediction for the trusted peer at time ' $t+1$ ' is by soliciting for its recommendations or reputation till time ' $\mathrm{t}$ ' and utilizing the Gaussian Distribution to determine the probability of the future Riskiness value within each range of the Riskiness scale. The rounded Riskiness value corresponding to the range of the highest probability is the future Riskiness value of the trusted peer. As mentioned in section 2, the Riskiness scale ranges from $(-1,5)$, with -1 denoted as Unknown Risk. So the future Riskiness value of a trusted peer is predicted in the domain of $(0,5)$. The probability of the future Riskiness value of the trusted peer at time ' $t+1$ ' within each range in this domain on the Riskiness scale is determined depending on its reputation or Riskiness values till time ' $t$ ', and the rounded Riskiness value corresponding to the range with the highest probability is the future Riskiness value of the trusted peer.

To determine the probability of the trusted peer's future Riskiness value within a range on the Riskiness scale, let us suppose that the trusting peer has collected recommendations from other peers according to the criteria of its interaction. Those recommendations are represented as:

$$
\left\{R_{1}, R_{2}, R_{3} \ldots R_{K}\right\}
$$

where $\mathrm{K}$ is the number of recommendations.

The Mean Riskiness Value $(\mu)$ is calculated as:

$$
\mu=\frac{1}{K} \sum_{i=1}^{K} R_{\mathrm{i}} \quad \text { Equation----1 }
$$

Accordingly the unbiased Sample Variance $\left(\sigma^{2}\right)$ is:

$$
\sigma^{2}=\frac{1}{K-1} \sum_{i=1}^{K}\left(R_{i}-\mu\right)^{2} \quad \text { Equation----2 }
$$

As defined in section 2, the future Riskiness value of a trusted peer is denoted as R'. Since R' $\sim\left(\mu, \sigma^{2}\right)$, then for any random variable $R^{\prime}$ according to Gaussian distribution, the probability of $R^{\prime}$ in a given range can be expressed as [10]:

$\mathrm{P}\left(\mathrm{a}<\mathrm{R}^{\prime}<\mathrm{b}\right)=\frac{1}{\sqrt{2 \prod} \sigma} \int_{\frac{a-\mu}{\sigma}}^{\frac{b-\mu}{\sigma}} \mathrm{e}^{\frac{-t 2}{2}} \mathrm{dt}$

\section{Equation----3}

Alternatively for any random variable R', its Cumulative Distributive Function (CDF) denoted by $\Phi$ in the range $-\infty<\Gamma<\infty$ is expressed in terms of its probability density function as [11]:

$$
\Phi(\Gamma)=\int_{-\infty}^{r} \frac{1}{\sqrt{2 \prod}} \mathrm{e}^{\frac{-t 2}{2}} \mathrm{dt}
$$

Similarly the probability of $\mathrm{R}^{\prime}$ in a given range, in terms of $\Phi$, the standard normal cumulative distributive function can be determined as [11]:

$$
\mathrm{P}\left(\mathrm{a}<\mathrm{R}^{\prime}<\mathrm{b}\right)=\Phi\left(\frac{b-\mu}{\sigma}\right)-\Phi\left(\frac{a-\mu}{\sigma}\right)
$$

\section{Equation----4}

As mentioned earlier the probability of the future Riskiness value within the domain of $(0,5)$ is determined. 
The rounded Riskiness value corresponding to the range which has the highest probability based on the past Riskiness values is chosen as the future Riskiness value of the trusted peer.

The concept will become clear when it is explained by taking an example in the next section.

\section{Example of Riskiness Value Prediction}

In this section we will explain the concept of predicting the future Riskiness value of a trusted peer by an example.

Let us consider that a trusting peer ' $A$ ' wants to interact with trusted peer ' $\mathrm{X}$ ' for a period of two weeks over context ' $C$ ' from 16/08/2005. Further let us assume that the criteria of the trusting peer ' $\mathrm{A}$ ' in the interaction are $\mathrm{C} 1, \mathrm{C} 2$ and $\mathrm{C} 3$ and the trusting peer ' $\mathrm{A}$ ' has not interacted with the trusted peer ' $\mathrm{X}$ ' before in context ' $\mathrm{C}$ '. In order to analyse the Risk that could be involved in the interaction, the trusting peer broadcasts its request asking for recommendations for the trusted peer ' $\mathrm{X}$ ' over a period of the last 4 weeks before 16/08/2005 i.e. from $19 / 07 / 2005$ to $15 / 08 / 2005$. The trusting peer wants to predict the Riskiness value of the trusted peer for the duration of its interaction i.e. from 16/08/2005 to $29 / 08 / 2005$. Consequently the total time space over which the trusting peer ' $A$ ' will analyse the Riskiness value of the trusted peer ' $\mathrm{X}$ ' is for a period of 6 weeks. In order to analyse the Riskiness of the trusted peer, the trusting peer wants to analyse its behaviour on a weekly basis during the time space. Hence the time slot is of 1 week.

The peers who had interacted with the trusted peer in question reply back with their recommendations in the form of Risk set as discussed in section 2.

Let us consider the trusting peer ' $A$ ' receives recommendations from peers ' $J$ ', 'K', 'D', 'E', ' $F$ ', 'G', 'H', and 'I'. The recommendations are:

From Peer ' $\mathrm{J}$ ':

\{Peer 'J', Peer 'X', Context 'C', 2, 3, ((C1, 1) $(\mathrm{C} 5,0))$, 2, 300, 20/07/2005, 24/07/2005, 0.8$\}$

From peer ' $\mathrm{K}$ ':

\{Peer ' $\mathrm{K}$ ', Peer ' $\mathrm{X}$ ', Context 'C', 5, 5, ((C1, 1) $(\mathrm{C} 2$, 1)), 5, 150, 26/07/2005, 31/07/2005, 0.5$\}$

From peer ' $\mathrm{D}$ ':

\{Peer 'D', Peer ' $\mathrm{X}$ ', Context 'C', 4, 4, ((C1, 1) (C3, 0)), 5, 1000, 12/08/2005, 13/08/2005, -1\}

From peer ' $\mathrm{E}$ ':

\{Peer 'E', Peer ' $\mathrm{X}$ ', Context 'C', 4, 3, ((C5, 1) (C2, 1)), 5, 500, 02/08/2005, 02/08/2005, UNKNOWN\}

From peer ' $F$ ':

\{Peer ' $F$ ', Peer ' $\mathrm{X}$ ', Context 'C', 5, 5, ((C2, 1) (C3, 1)), 3, 1200, 05/08/2005, 06/08/2005, 1 \}

From peer ' $\mathrm{G}$ ':

\{Peer 'G', Peer ' $\mathrm{X}$ ', Context 'C', 3, 3, ((C1, 1) $(\mathrm{C} 2,0)$ $(\mathrm{C} 3,1)), 5,1500,03 / 08 / 2005,06 / 08 / 2005,-2.6\}$
From peer ' $\mathrm{H}$ ':

\{Peer 'H', Peer 'X', Context 'C', 5, 5, ((C3, 1) (C6, 0)), 4, 500, 07/08/2005, 07/08/2005, UNKNOWN\}

From peer 'I':

\{Peer 'I', Peer 'X', Context 'C', 2, 2, ((C9, 1) $(\mathrm{C} 8,0))$, $1,100,10 / 07 / 2005,11 / 07 / 2005,1\}$

Classifying the above recommendations for trusted peer ' $\mathrm{X}$ ' as trustworthy, un-trustworthy and un-known, according to the Riskiness value of the recommending peer (RRP) and representing them according to their criteria as shown in table 1 :

\begin{tabular}{|c|c|c|}
\hline $\begin{array}{l}\text { Trustworthy } \\
\text { Recommendations }\end{array}$ & $\begin{array}{l}\text { Un-Known } \\
\text { Recommendations }\end{array}$ & $\begin{array}{l}\text { Un-Trustworthy } \\
\text { Recommendations }\end{array}$ \\
\hline $\begin{array}{c}\text { Peer 'J' } \\
\text { C1(1), C5(0) } \\
\text { Peer 'K' } \\
\text { C1(1), C2(1) } \\
\text { Peer 'D' } \\
\text { C1(1), C3(0) } \\
\text { Peer 'F' } \\
\text { C2 (1), C3(1) } \\
\text { Peer 'I' } \\
\text { C9 (1), C8(0) }\end{array}$ & $\begin{array}{c}\text { Peer 'E' } \\
\text { C5(1), C2(1) } \\
\text { Peer 'H' } \\
\text { C3(1), C6(0) }\end{array}$ & $\begin{array}{c}\text { Peer 'G' } \\
\text { C1(1), C2(0) }\end{array}$ \\
\hline
\end{tabular}

Table 1 classifying the recommendations according to their criteria

\subsection{Aggregating the recommendations according to the time slots:}

As mentioned in section 2, the trusting peer considers only the trustworthy and unknown recommendations and ignores the un-trustworthy recommendations. Continuing from the above example, the trusting peer ' $A$ ' will consider the recommendations of peers ' $J$ ', ' $\mathrm{K}$ ' ' $\mathrm{D}$ ', ' $\mathrm{F}$ ', 'I', 'E' ' $\mathrm{H}$ ' and discard the recommendation of peer ' $\mathrm{G}$ ' while predicting the Riskiness value of the trusted peer ' $\mathrm{X}$ '. The trusting should aggregate the recommendations of each time slot to arrive at a single Riskiness value for the trusted peer in that time slot.

Classifying the recommendations according to the time slot it can be concluded that:

Riskiness value of the trusted peer in the time slot of $19 / 07 / 2005$ to $25 / 07 / 2005$ :

There is one trustworthy recommendation for the trusted peer ' $\mathrm{X}$ ' from the recommending peer ' $\mathrm{J}$ ' in the time slot of $18 / 07 / 2005$ to $25 / 07 / 2005$. Hence the Riskiness value of the trusted peer ' $\mathrm{X}$ ' according to the recommendations is 2 for this time slot.

Riskiness value of the trusted peer in the time slot of $26 / 07 / 2005$ to $01 / 08 / 2005$ :

There is one trustworthy recommendation for the trusted peer ' $\mathrm{X}$ ' from the recommending peer ' $\mathrm{K}$ ' in the 
time slot of $26 / 07 / 2005$ to $01 / 08 / 2005$. Hence the Riskiness value of the trusted peer ' $X$ ' according to the recommendations is 5 for this time slot.

Riskiness value of the trusted peer in the time slot of $02 / 08 / 2005$ to $08 / 08 / 2005$ :

The recommendations from peers ' $\mathrm{E}$ ', ' $\mathrm{F}$ ', ' $\mathrm{H}$ ' are in the time slot of 02/08/2005 to 08/08/2005.

Hence aggregating the recommendations for trusted peer ' $\mathrm{X}$ ' to arrive at a single Riskiness value in the time slot of 02/08/2005 to 08/08/2005:

Recommendation from Peer 'E': 5

Recommendation from Peer 'F': 3

Recommendation from Peer ' $H$ ': 4

Peer ' $F$ ' is a trustworthy recommending peer and peer ' $\mathrm{E}$ ' and ' $\mathrm{H}$ ' are un-known recommending peers. Hence we propose that the recommendations from the trustworthy recommending peers must be given more weight than the ones from the unknown recommending peers when aggregating them.

The Riskiness value of the trusted peer in a time slot by aggregating the recommendations can be determined by using the following formulae:

$$
\begin{aligned}
& \operatorname{ROUND}\left(\alpha *\left(\frac{1}{N}\left(\sum_{i=1}^{N} \operatorname{RTRP} \mathrm{i}\right)\right)\right)+ \\
&\left(\beta *\left(\frac{1}{K}\left(\sum_{j=1}^{K} \operatorname{RURP}_{\mathrm{j}}\right)\right)\right)
\end{aligned}
$$

where RTRP $\mathrm{i}$ is the recommendation from the trustworthy recommending peer $\mathrm{i}$,

RURP ${ }_{j}$ is the recommendation from the unknown recommending peer $\mathrm{j}$,

$\mathrm{N}, \mathrm{K}$ are the number of trustworthy and unknown recommending peers,

$\alpha$ and $\beta$ are the weights attached to the equation which gives more significance to the trustworthy recommendations as compared to the unknown recommendations. In general $\alpha+\beta=1$.

It should be noted that by the above equation the Riskiness value of the trusted peer in a time slot by assimilating the recommendations should be set to 5 if it is greater than 5 .

Let us suppose that the trusting peer ' $\mathrm{A}$ ' gives a weight of 0.9 to trustworthy recommendations and a weight of 0.1 to un-known recommendations, i.e. $\alpha$ and $\beta$ respectively. Determining the Riskiness value of the trusted peer ' $\mathrm{X}$ ' in the time slot of $02 / 08 / 2005$ to $08 / 08 / 2005$ by aggregating the recommendations by using the above formulae:

Riskiness value of the trusted peer ' $\mathrm{X}$ ' in the time slot 01/08/2005 to $07 / 08 / 2005$ :

$$
\operatorname{ROUND}(0.9 *(3))+\left(0.1 *\left(\frac{1}{2}(5+4)\right)\right)=3
$$

Riskiness value of the trusted peer in the time slot of $09 / 08 / 2005$ to $15 / 08 / 2005$ :

Aggregating the recommendations and determining the Riskiness value of the trusted peer in the time slot of 09/08/2005 to $15 / 08 / 2005$ :

Recommendation from peer ' $\mathrm{D}$ ': 5

Recommendation from peer ' $I$ ': 1

But according to the Risk set the criteria of the recommending peer ' $\mathrm{I}$ ' does not match at all with the criteria of the trusting peer ' $A$ ' and so it is baseless for the trusting peer ' $A$ ' to consider its recommendation while aggregating the recommendations.

Hence the Riskiness value of the trusted peer ' $\mathrm{X}$ ' after aggregating the recommendations in the time slot $09 / 08 / 2005$ to $15 / 08 / 2005$ is 5 .

Once the trusting peer has determined the Riskiness values of the trusted peer till the time slot of its interaction then the future Riskiness value can be predicted by accumulating them.

\subsection{Predicting the future Riskiness value of peer 'X':}

Once the Riskiness values of the trusted peer ' $\mathrm{X}$ ' has been determined till the time slot of the trusting peer's interaction with it then its future Riskiness value can be predicted by using the concept proposed in section 4 .

Riskiness value of the trusted peer:

In time slot 19/07/2005 to 25/07/2005: 2

In time slot $26 / 07 / 2005$ to $01 / 08 / 2005: 5$

In time slot $02 / 08 / 2005$ to $08 / 08 / 2005: 3$

In time slot 09/08/2005 to 15/08/2005: 5

Determining the mean Riskiness value $(\mu)$ by using equation 1:

$$
\begin{gathered}
\mu=\frac{1}{K} \sum_{i=1}^{K} R_{\mathrm{i}} \\
\mu=3.75
\end{gathered}
$$

Accordingly the Sample Variance $\left(\sigma^{2}\right)$ calculated from equation 2 is:

$$
\begin{aligned}
& \sigma^{2}=\frac{1}{K-1} \sum_{i=1}^{K}\left(R_{i}-\mu\right)^{2} \\
& \sigma^{2}=2.25 \\
& \sigma=1.5
\end{aligned}
$$

Since the future Riskiness value $R^{\prime} \sim\left(\mu, \sigma^{2}\right)$, then according to Gaussian distribution the probability of $R^{\prime}$ in a given domain of $(0,5)$ can be determined according to equation 3 . Within the domain of $(0,5)$ there are 10 
different ranges. The probability of the future Riskiness value within each range is determined, and the rounded Riskiness value of the range with the highest probability is the future Riskiness value of the trusted peer.

Hence by using equation 3 determining the future Riskiness value of the trusted peer in each range:

$$
\mathrm{P}\left(0<R^{\prime}<0.4\right)=0.0067=0.67 \%
$$

Similarly,

$$
\begin{aligned}
& \mathrm{P}\left(0.5<R^{\prime}<1\right)=0.0182=1.82 \% \\
& \mathrm{P}\left(1<R^{\prime}<1.4\right)=0.0258=2.58 \% \\
& \mathrm{P}\left(1.5<R^{\prime}<2\right)=0.0562=5.62 \% \\
& \mathrm{P}\left(2<R^{\prime}<2.4\right)=0.0611=6.11 \% \\
& \mathrm{P}\left(2.5<R^{\prime}<3\right)=0.1052=10.52 \% \\
& \mathrm{P}\left(3<R^{\prime}<3.4\right)=0.1005=10.05 \% \\
& \mathrm{P}\left(3.5<R^{\prime}<4\right)=\mathbf{0 . 1 3 2 5}=\mathbf{1 3 . 2 5 \%} \\
& \mathrm{P}\left(4<R^{\prime}<4.4\right)=0.1028=10.28 \% \\
& \mathrm{P}\left(4.5<R^{\prime}<5\right)=0.1052=10.52 \%
\end{aligned}
$$

The range of the Riskiness values between 3.5 and 4 has the highest probability of $13.25 \%$.

$$
\text { ROUND }\left(3.5<R^{\prime}<4\right)=4
$$

Hence depending on the previous Riskiness values that the trusting peer assimilated by soliciting recommendations according to each time slot, it can be concluded that the future Riskiness value of the trusted peer in the time slot of $16 / 08 / 2005$ to $22 / 08 / 2005$ is going to be 4 . Further depending on the previous time slots the trusting peer ' $A$ ' can further predict the Riskiness value of the trusted peer ' $\mathrm{X}$ ' in the time slot of $23 / 08 / 2005$ to 29/08/2005.

\section{Riskiness Value Evaluation}

The accuracy of the predicted future Riskiness value R' can further be determined by evaluating the probability of the predicted Riskiness value $\mathrm{R}$ ' being better than a value $v$, where $v \in[0,5]$ and $v \neq R^{\prime}$, according to the past Riskiness values or the recommendations given by other peers by using the following equation:

$$
\mathrm{P}_{\mathrm{R}^{\prime}}^{\mathrm{X}}(v)=\frac{\mathrm{P}\left(v<\mathrm{R}^{\prime} \leq 5\right)}{\mathrm{P}\left(0<\mathrm{R}^{\prime} \leq 5\right)} \quad \text { if } v<\mathrm{R}^{\prime}
$$

Or

$$
\mathrm{P}_{\mathrm{R}^{\prime}}^{\mathrm{X}}(v)=\frac{\mathrm{P}\left(v>\mathrm{R}^{\prime} \geq 0\right)}{\mathrm{P}\left(5>\mathrm{R}^{\prime} \geq 0\right)} \quad \text { if } v>\mathrm{R}^{\prime} .
$$

Hence continuing from the example discussed in the previous section and determining the accuracy of the predicted future Riskiness value $\mathrm{R}$ ' being better than any other value $v$ on the Riskiness scale:

$$
\begin{aligned}
& \text { Predicted Future Riskiness value }\left(\mathrm{R}^{\prime}\right)=4 \\
& \mathrm{P}_{4}^{\mathrm{X}}(0)=1 \text { or } 100 \% \\
& \mathrm{P}_{4}^{\mathrm{X}}(1)=0.98 \text { or } 98 \% \\
& \mathrm{P}_{4}^{\mathrm{X}}(2)=0.89 \text { or } 89 \% \\
& \mathrm{P}_{4}^{\mathrm{X}}(3)=0.66 \text { or } 66 \% \\
& \mathrm{P}_{4}^{\mathrm{X}}(5)=1 \text { or } 100 \%
\end{aligned}
$$

Hence these probabilities proves that the predicted future Riskiness value R' determined by the proposed model according to the previous reputation of the trusted peer or by the recommendations given by the recommending peer is better than any other value on the Riskiness scale. This proves that the predicted Riskiness value is accurate and can be considered as the probable future Riskiness value in making a decision.

Depending on the past and the predicted future Riskiness values of the trusted peer ' $\mathrm{X}$ ', the trusting peer ' $A$ ' can analyse the Risk better and then decide whether to interact with it or not. If the trusting peer interacts with the trusted peer ' $X$ ', then after its interaction it should assign a Riskiness value to the trusted peer, depending on the level of un-committed behaviour in the interaction. At a later time when any other peer asks for recommendation about trusted peer ' $\mathrm{X}$ ' from the peer ' $\mathrm{A}$ ' in context ' $\mathrm{C}$ ' then it can give this Riskiness value as its recommendation in the form of Risk set.

\section{Conclusion}

In this paper we proposed a method by which the trusting peer can predict the future Riskiness value of a trusted peer. Based on the future Riskiness value, the trusting peer can get an indication of the Risk that could be involved in dealing with a trusted peer once the interaction starts and this would help the trusting peer in making its decision to proceed in the interaction or not with the trusted peer. The total time space in which the trusting peer wants to analyze the Riskiness value of the 
trusted peer is divided into different non-overlapping time slots. The Riskiness value or the reputation of the trusted peer in the past time slots is determined by the trusting peer by asking recommendations from other peers. Based on the Riskiness value for the trusted peer in the previous time slots the future Riskiness value is determined by using Gaussian distribution. Further the predicted Riskiness value ( $\left.R^{\prime}\right)$ is further proved for its correctness by determining its probability of being better than any other value $(v)$ on the Riskiness scale.

\section{References}

[1] Chan, H., R. Lee, T.S. Dillon and E. Chang, ECommerce and its Applications, 1 edition, John Wiley and Sons, Ltd.

[2] S. Greenland, 'Bounding analysis as an inadequately specified methodology', Risk Analysis, vol. 24, no. 5, pp. 1085-1092, 2004.

[3] O.K.Hussain, E. Chang, F.K. Hussain, T.S. Dillon and B. Soh, 'A Methodology for Determining Riskiness in peer-to-Peer Communication', Proceedings of the $3^{\text {rd }}$ International IEEE Conference on Industrial Informatics, Perth, August 2005, pp 421-432.

[4] J. Carter and A.A. Ghorbani, 'Towards a formalization of Trust' Web Intelligence and Agent Systems, Vol. 2, No. 3, pp. 167-183, March 2004.

[5] O.K Hussain, E. Chang, F.K. Hussain, T.S. Dillon and B. Soh, "Modeling the Risk Relationships and Defining the Risk Set (Accepted for publication)," CollECTeR Latam 2005, to be published, Chile, 2005.
[6] O.K Hussain, E. Chang, F.K. Hussain, T.S. Dillon and B. Soh, "Context Based Riskiness Assessment" (Accepted for publication), IEEE TENCON 2005, to be published, Melbourne, Australia, 2005.

[7] O.K Hussain, E. Chang, F.K. Hussain, T.S. Dillon and B. Soh, "Context and Time Based Riskiness Assessment for Decision Making" (Submitted for Acceptance in The IEEE International Conference on Sensor Networks, Ubiquitous, and Trustworthy Computing (SUTC2006), Taiwan, June 2006.

[8] O.K. Hussain, E. Chang, B. Soh, F.K. Hussain, and T.S. Dillon 'Factors of Risk Variance in Decentralized Communications', European Institute of Computer Antivirus Research, April 2005, Malta, pp 162-170.

[9] O.K. Hussain, E. Chang, F.K. Hussain, T.S. Dillon and B. Soh. "Risk in Trusted Decentralized Communications", Proceedings of the International Workshop on Privacy Data Management in Conjunction with 21st International Conference on Data Engineering (ICDE PDM 2005) Tokyo, April 2005, pp 63-67.

[10] Weiss, N.A., 'A Course in Probability', Pearson Education Inc. 2005, ISBN 0-201-77471-2

[11] Karr, A.F., 'Probability', Springer-Verlag New York, Inc. 1993, ISBN 0-387-94071-5. 